\title{
Variable Time Normalization Analysis: General Graphical Elucidation of Reaction Orders from Concentration Profiles
}

DOI:

10.1002/anie.201609757

\section{Document Version}

Accepted author manuscript

Link to publication record in Manchester Research Explorer

\section{Citation for published version (APA):}

Bures Amat, J. (2016). Variable Time Normalization Analysis: General Graphical Elucidation of Reaction Orders from Concentration Profiles. Angewandte Chemie - International Edition, 55(52), 16084-16087.

https://doi.org/10.1002/anie.201609757

\section{Published in:}

Angewandte Chemie - International Edition

\section{Citing this paper}

Please note that where the full-text provided on Manchester Research Explorer is the Author Accepted Manuscript or Proof version this may differ from the final Published version. If citing, it is advised that you check and use the publisher's definitive version.

\section{General rights}

Copyright and moral rights for the publications made accessible in the Research Explorer are retained by the authors and/or other copyright owners and it is a condition of accessing publications that users recognise and abide by the legal requirements associated with these rights.

\section{Takedown policy}

If you believe that this document breaches copyright please refer to the University of Manchester's Takedown Procedures [http://man.ac.uk/04Y6Bo] or contact uml.scholarlycommunications@manchester.ac.uk providing relevant details, so we can investigate your claim.

\section{OPEN ACCESS}




\section{Variable Time Normalization Analysis: General Graphical Elucidation of Reaction Orders from Concentration Profiles}

\section{Jordi Burés*}

The University of Manchester, School of Chemistry

Oxford Road, M13 9PL Manchester (UK)

E-mail: jordi.bures@manchester.ac.uk

\begin{abstract}
The recent technological evolution of reaction monitoring techniques has not been paralleled by the development of modern kinetic analyses. The analyses currently used disregard part of the data acquired, thus requiring an increased number of experiments to obtain sufficient kinetic information for a given chemical reaction. Herein, we present a simple graphical analysis method that takes advantage of the data-rich results provided by modern reaction monitoring tools. This analysis uses a variable normalization of the time scale to enable the visual comparison of entire concentration reaction profiles. As a result, the order in each component of the reaction, as well as $k_{o b s}$, is determined with just a few experiments using a simple and quick mathematical data treatment. This analysis facilitates the rapid extraction of relevant kinetic information and will be a valuable tool for the study of reaction mechanisms.
\end{abstract}

Reaction monitoring techniques that provide a vast amount of data during the progress of a reaction are becoming increasingly more common in academic and industrial environments. To more effectively exploit these technologies, the development of new kinetic analyses is necessary. The latest breakthrough in kinetic methods was the well-known reaction progress kinetic analysis (RPKA) described by Blackmond in 2005. ${ }^{[1]}$ This analysis enables the detection of significant catalyst deactivation and product inhibition (Figure 1a), the elucidation of the order in catalyst (Figure 1b), and the determination of the order in reagents (Figure 1c). RPKA graphically interrogates the data obtained during the entire course of a reaction under synthetically relevant conditions. When compared to classical kinetic analyses, RPKA is simpler to perform and requires fewer experiments to provide more useful and relevant information. Nevertheless, RPKA requires rate data, which is mainly obtained by isothermal calorimetry (ITC), a technique that is not suitable for most reactions. Therefore, there is an obvious interest in developing analogous reaction progress kinetic analyses that directly use conversion reaction profiles. In this context, Blackmond and co-workers described the time-adjusted method ${ }^{[2]}$ to detect significant catalyst deactivation and product inhibition (Figure 1d), and we described the normalized time scale method ${ }^{[3]}$ to elucidate the order in catalyst (Figure 1e). We herein report a method to determine the order in any component of a reaction by direct visual comparison of reaction concentration profiles (Figure 1f).

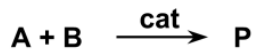

Reaction Progress Kinetics Analysis

Rate profiles

(obtained by ITC)

a) same excess ${ }^{[1]}$

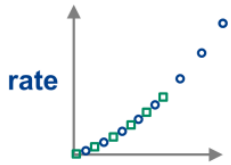

[A]

b) different catalyst loading ${ }^{[1]}$

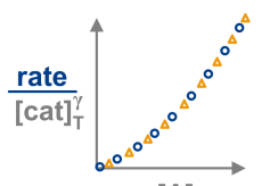

[A]

c) different excess ${ }^{[1]}$

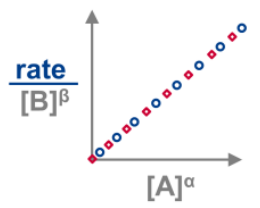

Concentration profiles

(obtained by NMR, IR, UV, HPLC, GC, ..)

d) time adjustment ${ }^{[2]}$

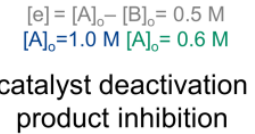
product inhibition

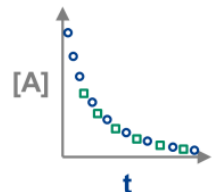

e) normalized time scale ${ }^{[3]}$

Figure 1. The work presented here completes the set of analyses to perform reaction progress kinetic analysis using reaction concentration profiles.

The method presented here uses the popular graphical interrogation of kinetic data, ${ }^{[1-3]}$ which takes advantage of the human visual capacity to easily, quickly, and accurately identify tendencies and patterns. The profiles of experiments differing in the concentration of one reactant, $\mathbf{A}$, will only overlay when the time axis is replaced by the time integral of the concentration of $\mathbf{A}$ raised to the correct power $\alpha$ [Eq.(1)]. ${ }^{[4]}$ This function is a priori unknown, but it can be approximated by using the trapezoid rule [Eq. (1)]. All of the values necessary to apply this formula are known, either because they have been measured experimentally or because they can be deduced from the concentration profiles of another reaction component if the stoichiometry is known. Therefore, the construction of the new time scale is easy and quick to perform by using any spreadsheet, without the need for sophisticated kinetic analysis packages

$\int_{t=0}^{t=n}[\mathrm{~A}]^{\alpha} \mathrm{d} t=\sum_{i=1}^{n}\left(\frac{[\mathrm{A}]_{i}-[\mathrm{A}]_{i-1}}{2}\right)^{\alpha}\left(t_{i}-t_{i-1}\right)<\mathrm{ZS}>(1)$ 
The method normalizes the time between each pair of data points by the average concentration of these points. More intuitively, normalizing the time scale for the concentration of each component of the system removes the kinetic effect of that component from the reaction profile. The normalization of the time scale can be extended to as many reaction components as desired, regardless of whether their concentration is constant or variable during the reaction course. When the normalization is applied to all of the components with a kinetic effect in the reaction, the result is a plot with a straight line with a slope equal to $\left\langle\mathrm{M}->k_{\mathrm{obs}}{ }^{[5]}\right.$ This linearization could, in principle, be used to estimate the orders in all of the components of a reaction as well as the $k_{\mathrm{obs}}$ value from a single reaction profile. However, this option requires much more accurate experimental measurements than using the overlay method. As it is usually easier to perform an extra experiment rather than to increase the accuracy of the analysis method used, the graphical overlay comparison should be preferred to individually determine the order in each parameter.
Figure 2 shows the application of this approach to a simulated two-substrate catalyzed reaction. Product concentration traces have been drawn, instead of those of the reactants, to facilitate the comparison between different experiments. Nevertheless, plots can be constructed using the concentrations of any of the reactants depending on the data available. Figure $2 \mathrm{a}$ shows the product concentration profiles against the variable time scale normalized in $\mathbf{A}\left(\Sigma[\mathbf{A}]^{\alpha} \Delta t\right)$ for identical experiments, except for the initial concentration of $\mathbf{A}$. The effect of different orders is shown; the correct order in $\mathbf{A}$, in this case one, produces the overlay of both traces. Figure $2 b$ shows the overlay for the right order in $\mathbf{B}$ by using the plots of [P] against $\Sigma[\mathbf{B}]^{\beta} \Delta t$ for two experiments with different concentrations of $\mathbf{B}{ }^{[6]}$ The plots in Figure $2 \mathrm{c}$ demonstrate the overlay for an order of one in catalyst using the product concentration profiles against $\Sigma[\mathrm{cat}]_{\mathrm{T}}^{\gamma} \Delta t$ for two reactions with different catalyst loadings. If the catalyst is not significantly deactivated during the reaction, its total concentration is constant, and $\Sigma[\mathrm{cat}]_{\mathrm{T}}^{\gamma} \Delta t$ becomes $t[\mathrm{cat}]_{\mathrm{T}}^{\gamma}$.

a) Order in $A$
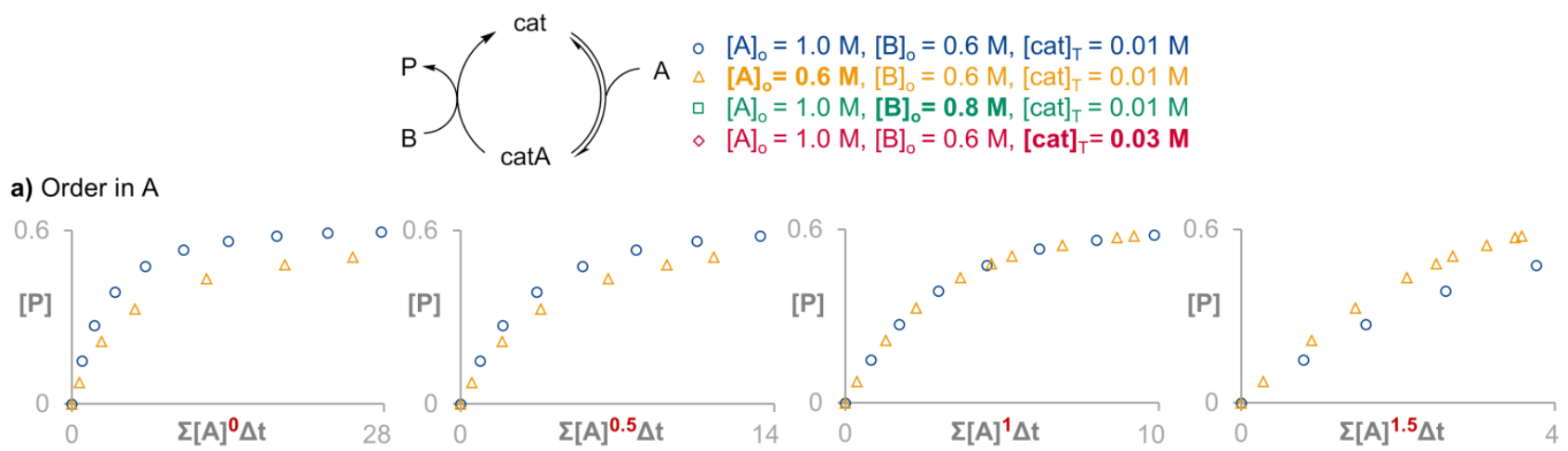

b) Order in B
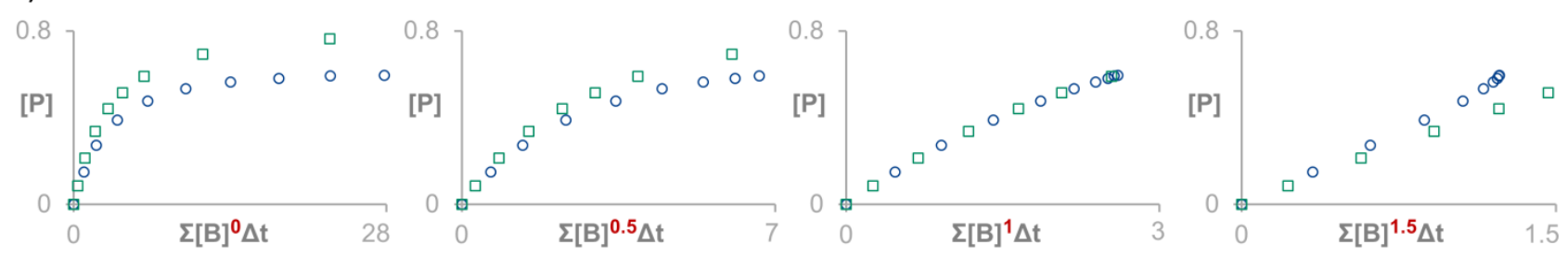

c) Order in catalyst
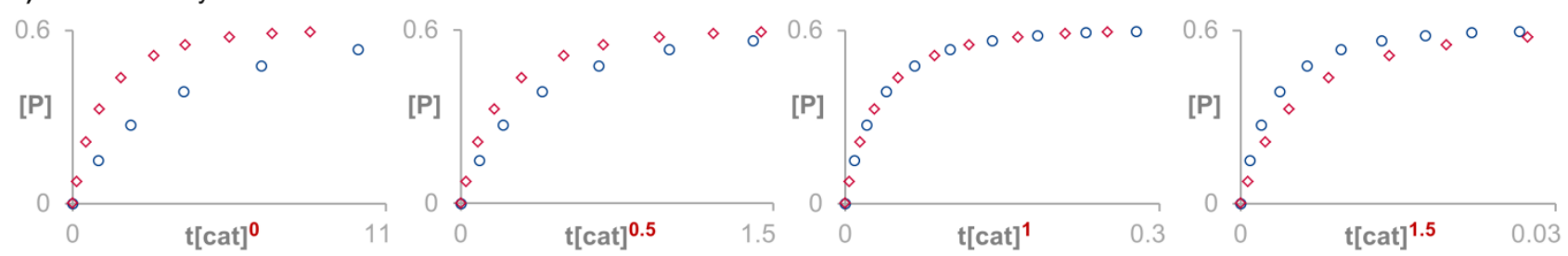

d) Determination of $\mathrm{k}_{\mathrm{obs}}$
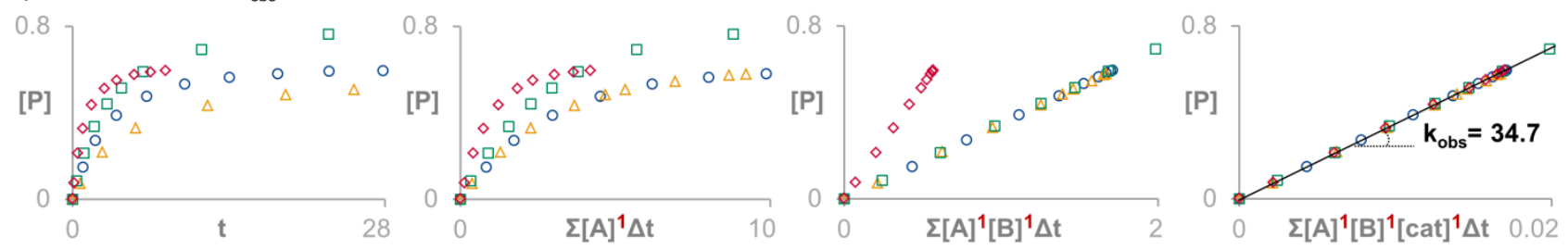

Figure 2. Variable time normalization analysis enables the determination of the order in substrate $\mathbf{A}(\mathrm{a})$, substrate $\mathbf{B}$ (b), and catalyst (c). The sequential normalization of the time scale in $\mathbf{A}, \mathbf{B}$, and catalyst leads to the overlay of all reaction profiles in a straight line with a slope that corresponds to $k_{\mathrm{obs}}(\mathrm{d}) \cdot{ }^{[7]}$ 
Therefore, the variable time normalization method presented herein encompasses the normalized time scale method previously described. ${ }^{[3]}$ Figure $2 \mathrm{~d}$ shows the sequential evolution of the curves for all four experiments when the individual effects of the concentrations of $\mathbf{A}, \mathbf{B}$, and catalyst are simultaneously subtracted. The plot with the effects of all of the components removed shows four overlaid straight curves with a slope of $34.7^{\wedge} \mathrm{M}^{<\mathrm{M}->2} \wedge^{<\mathrm{M}->1}$, which corresponds to $k_{\mathrm{obs}}$ for this reaction. This is an example of the extreme normalization method mentioned above.

As the variable time normalization method presented here can be used to determine the order in reaction components whose concentrations change during the reaction, the method is also suitable to elucidate the order in catalyst of reactions that suffer from significant catalyst deactivation. To do so, the concentration of the remaining active catalyst has to be tracked during the reaction. Figure 3 shows the elucidation of the order in catalyst of the same reaction shown in Figure 2, but where more than half of the catalyst becomes deactivated during the reaction. Figure $3 \mathrm{a}$ shows the remaining active catalyst at each conversion point for two reactions run with different catalyst loadings. Even with the larger relative error in the measurement of the concentration of catalytic species compared to those of the reactants, it is possible to determine the correct order in catalyst, in this case one (Figure 3b), by using the variable time normalization analysis.

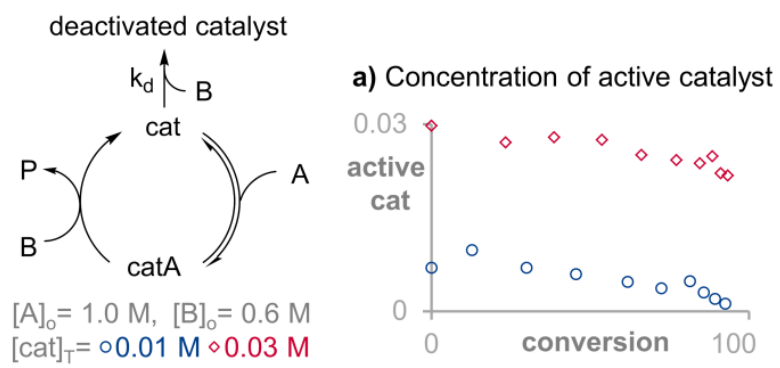

b) Order in catalyst

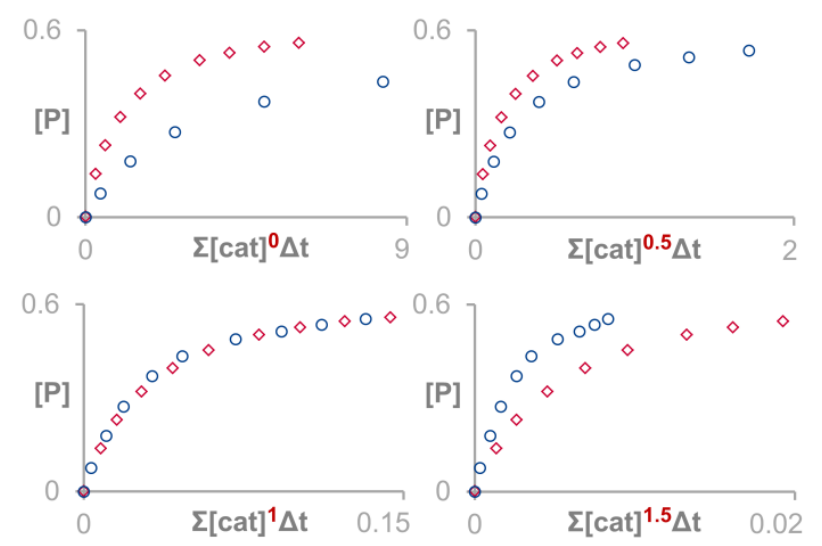

Figure 3. This approach can also be used to determine the order in catalyst when its concentration changes during the course of a reaction owing to deactivation processes. ${ }^{[7]}$

The reaction order in a substrate can change during the course of some reactions, especially for those involving catalysis. To determine the exact order for each section of the reaction, it is necessary to restrict the analysis to that specific section. Nevertheless, this level of accuracy is often not required in mechanistic studies, and an average order for the entire reaction course is generally sufficient. Figure 4 shows the analysis of the order in reagents in the hydrolytic kinetic resolution of terminal epoxides described by Jacobsen and coworkers. ${ }^{[8]}$ Owing to the complexity of the mechanism of this reaction, the orders in epoxide and water change during the course of the reaction and depend on the initial conditions. An elasticity analysis $(\varepsilon)$, which describes the change in the order of the reactants during the course of each reaction, is shown in Figure 4a,c. ${ }^{[9]}$ The variable time normalization analyses for the epoxide and water are shown in Figures $4 b$ and d, respectively. For both substrates, the analysis is a valuable tool to determine the average orders for the regime of the reaction examined, which amount to approximately 0.60 for the epoxide and 0.75 for water. These orders, together with the order in catalyst, ${ }^{[3]}$ are consistent with the proposed mechanism.

Variable time normalization analysis preserves the most attractive advantages of RPKA and the normalized time scale method. ${ }^{[1-3]}$ Only a few experiments are needed because each data point is used in a multipoint comparison, instead of discarding information by describing an entire reaction profile with a single initial rate or $k_{\text {obs. }}$. Moreover, it can deal with experiments containing large errors or few data points. Experiments are run under synthetically relevant conditions, avoiding the study under unrealistic flooding (pseudo-firstorder) conditions of one of the reaction components. The analysis uses the entire reaction profile, and therefore, it provides information on the entire reaction course instead of extrapolating the information obtained at the initial stages of the reaction. Finally, it is easy and quick to perform by any non-expert in chemical kinetics.

The visual analysis of the data makes the method simple to use and facilitates the intuitive interpretation of the results, but it also entails some limitations. There is no mathematical description for the error in the order, although it is usually easy to identify a range of orders leading to a good overlay. Furthermore, because the analysis is visual, it is important to rescale the abscissa axis for a fair comparison of different orders, as has been done in the Figures shown in this Communication. As for any other analysis method, the parameters that can affect the kinetics of the reaction, such as pressure and temperature, should be kept constant across each set of experiments.

In conclusion, a general method to elucidate the order in any component of a reaction has been presented. This method works well irrespective of how the concentration of the analyzed substance changes during the progress of the reaction. It is easy and quick to perform, and it directly uses the ubiquitous concentration against time reaction profiles. Therefore, the method is expected to be of particular value to non-experts in kinetics that intend to determine the orders of reactions for mechanistic purposes. 


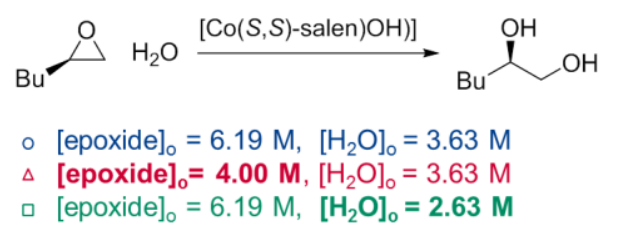

a) Elasticity coefficient for epoxide ${ }^{[9]}$

b) Order in epoxide
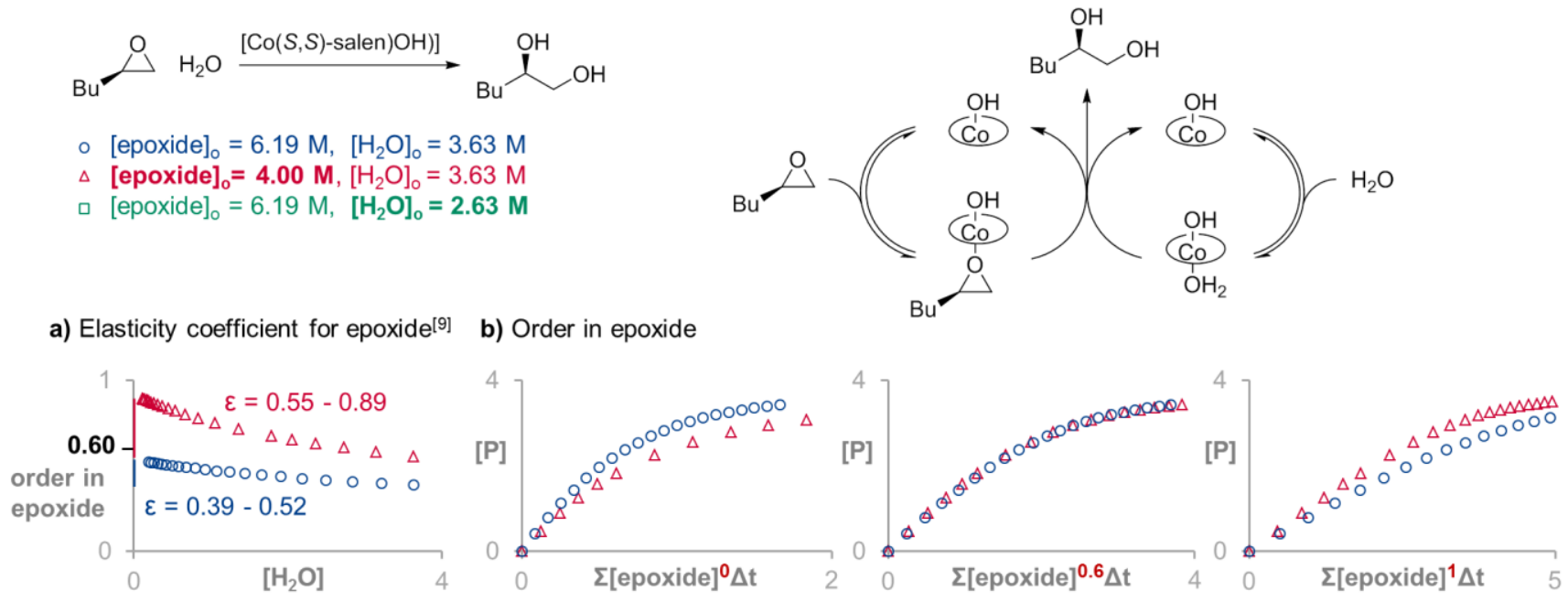

c) Elasticity coefficient for $\mathrm{H}_{2} \mathrm{O}^{[9]}$

d) Order in $\mathrm{H}_{2} \mathrm{O}$
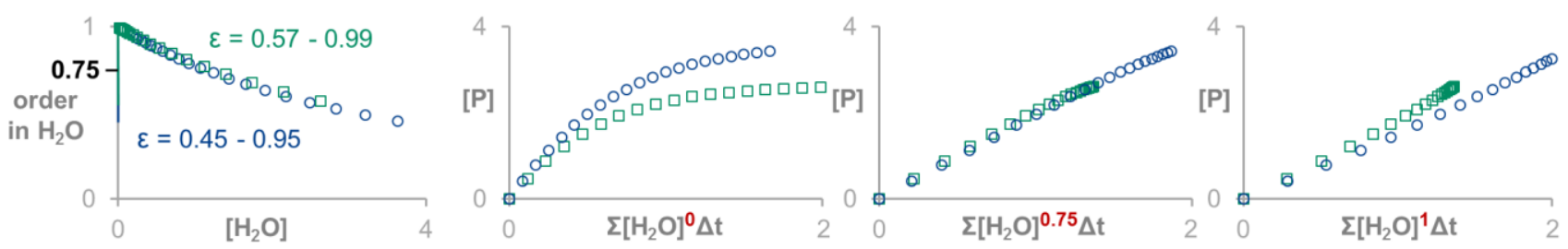

Figure 4. Variable time normalization analysis can be used to determine average values for the order in reactants if these change during the progress of a reaction. The elasticity analysis ${ }^{[4, \wedge]}$ (shown in (a) and (c) for the epoxide and water, respectively) confirms that the average orders obtained with the method presented herein ( 0.6 for the epoxide and 0.75 for water, as shown in (b) and (d), respectively) are true representations of the real values. ${ }^{[7]}$

Keywords: catalysis $\bullet$ kinetic analysis $\bullet$ reaction kinetics $\bullet$ order of reaction $\bullet$ reaction mechanisms

[1] a) D. G. Blackmond, Angew. Chem. Int. Ed. 2005, 44, 4302-4320; Angew. Chem. 2005, 117, 4374-4393; b) J. S. Mathew, M. Klussmann, H. Iwamura, F. Valera, A. Futran, E. A. C. Emanuelsson, D. G. Blackmond, J. Org. Chem. 2006, 71, 4711-4722.

[2] R. D. Baxter, D. Sale, K. M. Engle, J.-Q. Yu, D. G. Blackmond, J. Am. Chem. Soc. 2012, 134, 4600-4606.

[3] J. Bures, Angew. Chem. Int. Ed. Engl. 2016, 55, 20282031; Angew. Chem. 2016, 128, 2068-2071.

[4] See Supporting Information.

[5] The slope is $\mathrm{k}_{\mathrm{obs}}$ when the concentration of a product is plotted and $-\mathrm{k}_{\mathrm{obs}}$ when the concentration of a reactant is plotted.

[6] The reaction profiles used to determine the order in B could have been the same ones used to determine the order in A by taking as a starting point the time when the faster reaction has $[\mathrm{A}]=0.6 \mathrm{M}$ and $[\mathrm{B}]=0.2 \mathrm{M}$, which is the same as shifting the curve in both axis.

[7] The simulations have been run using COPASI: S. Hoops, S. Sahle, R. Gauges, C. Lee, J. Pahle, N. Simus, M. Singhal, L. Xu, P. Mendes, U. Kummer, Bioinformatics 2006, 22, 3067-3074.
[8] a) D. D. Ford, L. P. Nielsen, S. J. Zuend, C. B. Musgrave, E. N. Jacobsen, J. Am. Chem. Soc. 2013, 135, 15595-15608; b) L. P. C. Nielsen, C. P. Stevenson, D. G. Blackmond, E. N. Jacobsen, J. Am. Chem. Soc. 2004, 126, 1360-1362.

[9] J. Bures "What is the order of a reaction?" Top. Catal. 2017, accepted. 